\title{
THE WIND AND THE CITY: EVALUATING THE LIMITS TO APPLY NATURAL VENTILATION FOR THERMAL COMFORT IN DENSE URBAN SETTLEMENTS USING A COMPUTATIONAL FLUID DYNAMICS TOOL.
}

\author{
R. C. V. Leite ${ }^{1}$, A. B. Frota ${ }^{1}$ \\ ${ }^{1}$ Faculty of Architecture and Urbanism at the University of São Paulo (renancid@bol.com.br)
}

\begin{abstract}
Urbanization can deeply compromise the city's atmosphere through the modification of the environmental parameters such as air temperature and wind patterns. Therefore, great emphasis should be placed on heat generation and changes on natural ventilation conditions that directly lead to thermal discomfort, compromising building's energetic performance. Specifically in cities with hot, humid climate, the case of Fortaleza, Ceará, Brazil (latitude $3^{\circ} 43^{\prime} S$ ), natural ventilation is the main passive strategy to obtain thermal comfort. Understanding the physical phenomenon and the aspects that influence natural ventilation process becomes crucial to objectively use the wind potential for naturally cooling of buildings. . However, it is becoming a major problem to naturally ventilate the building's façades in dense urban centers, compromising the wind access to habitations. The airflow around buildings creates a pressure distribution over buildings façades, which it is an essential aspect to natural ventilation process. By creating high and low pressure zones over different parts of the building, the wind induces the air movement inside the building and once the city's spatial organization directly influences building's natural ventilation through the modification of pressure coefficients $(C p)$ over its surfaces. Once computational fluid mechanics is a valuable tool to analyze the wind behavior within urban areas it is widely used in researches to determine air movement characteristics of a given area or inside the buildings this tool is applied in this research, which evaluates different urban densification scenarios to determine the constructive limits that result in better or worse conditions to the air movement in high-rise apartments. The investigation is largely based on a computational Fluid Dynamics (CFD) tool to analyze the airflow around buildings and calculate the pressure coefficient and velocity field that are applied in the airflow predictions inside the apartments. The objective is to adopt a set of urban and architectural solutions in order to dissipate the heat and improve indoor thermal conditions using natural ventilation, reducing the need for artificial conditioning.
\end{abstract}

Keywords: Natural ventilation, Urban densification, Pressure coefficient, Computational fluid mechanics, Thermal comfort. 


\section{INTRODUCTION}

The city's atmosphere can be deeply compromised by the urbanization process. Through the modification of the environmental parameters such as air temperature by the alteration of the heat balance within the city, some effects such as the urban heat island and thermal inversion are generated. Also the air pollution, changes in the wind pattern and precipitation are more severe in dense urban settlements. Climate change caused by the city is documented in its regional and local repercussions [1 - 4]. Among these effects, the excessive heat generation and changes in natural ventilation are highlighted because they lead to thermal discomfort and compromise the energetic performance of buildings.

Advances on research about the aspects involved in the city's dynamic development and its relation to climate are fundamental to comprehend the thermal response of the built environment, contributing to local urban planning process, as attested by several studies [5 7].

Currently, energy consumption of buildings is in the center of the discussion about environmental preservation and sustainable development. Buildings are major consumers of natural resources and energy, using between $30 \%$ and $40 \%$ of global primary energy. It corresponds to $40 \%$ in the United States and European countries, reaching 50\% in the UK. Regarding $\mathrm{CO}_{2}$ emissions, building sector accounts for approximately $45 \%$ of total anthropogenic releases into the atmosphere [8].

Despite the lack of a consensus about the sustainability concept, it is possible to identify some necessary steps to achieve certain levels of development in balance with the environment. Some of these steps involve changes in energy consumption patterns, updating urban legislation, some factual improvement in the waste and water treatment and in energy generation among other issues.

Energy consumption has increased worldwide due to the lifestyle and population's current demands. According to statistical analysis, the upward trend in energy consumption will continue [9]. It should be noted, however, that the rate of energy consumption in less developed countries (Southeast Asia, Middle East, South America and Africa) will grow at an annual rate of $3.2 \%$, surpassing in 2020 the energy demand of more developed countries (North America, Europe, Japan, Australia and New Zealand).

As pointed out in recent researches, energy consumption by heating, ventilation and air conditioning (HVAC), previously seen as luxuries, have now become almost essential once thermal comfort in buildings evolved since the energy efficient approach. However, it still corresponds to the largest end-use energy in the residential sector [10].

Therefore within the buildings the use of natural resources for passive cooling is emphasized in order to reduce the energy consumption. Also, developing energy efficient buildings in their contexts is fundamentally necessary towards a more sustainable environment.

Natural ventilation, where is possible its application, provides fresh air to building's occupants, contributing to healthiness once it plays a crucial role in oxygen supplying and diluting carbon dioxide. Also, it reinforces the cooling sensation through the acceleration of thermal exchanges between the individual and its surroundings [11; 12].

More specifically, in hot and humid climate regions, where there is a little variation in 
air temperature during the day and high levels of humidity, controlling solar radiation and increasing the air movement within the urban fabric and inside the buildings becomes fundamentally necessary in order to avoid thermal discomfort sensation.

However, the appropriate application of the wind potential for passive cooling of buildings requires understanding the aspects of the physical phenomenon and the factors that influence the natural ventilation process. It includes variable factors such as local wind characteristics, the forms of the surrounding built environment and also internal factors such as openings sizes, locations and characteristics that structurally affect natural ventilation performance of buildings.

From a practical view, as the wind flows and passes through a building it creates a pressure field over its facades. This pressure distribution is an essential part of the natural ventilation process once it creates zones of high and low pressures on different sides of the building. The differences between high pressure and low pressure zones induce the air movement inside it. Therefore, this flow is essentially dependent on the pressure coefficient on the building's facades.

Pressure coefficient $(\mathrm{Cp})$ is an empirical and dimensionless parameter that characterizes the airflow. It represents the pressure changes induced by air movement and which are caused by the influence of the surroundings characteristics on local wind behavior $[13 ; 14]$. Consequently, $\mathrm{Cp}$ values are modified according to local topography and terrain roughness.

Commonly, $\mathrm{Cp}$ values are obtained through algorithms based on wind tunnel tests using low porosity or solid models. However, obtaining $\mathrm{Cp}$ data according to this method is not always possible, due to high cost of these experiments, equipment and expertise involved [15].

When determining pressure coefficient values through the wind tunnel technique is not achievable, it is possible to define it using computational fluid dynamics programs, widely known as cfd tools [16]. Also, with appropriate conditions and mesh parameterization, the adoption of an appropriate turbulence model and the systematization of the steps of the simulation, it is possible to determine reliable values of $\mathrm{Cp}$ for thermal comfort studies [15].

Applying a cfd tool to simulate the wind patterns proved to be a useful and accurate way to analyze the climate suitability for built environments in several studies. The method was tested in the assessment of natural ventilation conditions in various works [15 - 22] identifying the influence of different urban forms on the airflow in the built environment.

Although natural ventilation within the urban space has been studied in several researches the interference of the urban form over indoor air movement remains largely unexplored [22]. Once the obstacles in the neighborhood significantly affect $\mathrm{Cp}$ values and also considering that the study about urban densification and environmental conditions still need some answers, it becomes crucial to understand the limits and possibilities of the city growth in its relation to the need of natural ventilation inside the buildings.

The choice for the city of Fortaleza, in the northeast of Brazil, is due to the fact that the city's current configuration has several environmental problems as results of changes in its natural components, compromising the inhabitant's life quality. The recent and rapid urban growth is mainly characterized by a disregarding view of environmental issues that should be involved in the city development. 
This paper presents the first steps and methods adopted to carry out this research about urban densification and its effects on indoor natural ventilation assessment. Also, the preliminary results of pressure coefficient on the façade of the model building in 08 different urban density scenarios.

\subsection{Research objective}

The major objective of this research is to evaluate how different urban built density arrangements affect indoor natural ventilation conditions through the modification of pressure coefficient on residential building's façades.

This study analyzes some examples of urban density morphologies, presented here as the first virtual tridimensional models used in this research, in its relation to the modification of the wind pressure field around a high-rise residential building used as a model. The modification of the pressure field over its façades might compromise the performance of natural ventilation inside the apartments, leading to thermal discomfort and increasing energy consumption by the use of mechanical means of cooling.

\section{RESEARCH METHODS}

Initially, a comprehensive study about the natural ventilation phenomenon and the limits of its application for thermal comfort for building's occupants in hot and humid climate has been performed. In addition, a detailed review about adaptive comfort indexes and its application for naturally ventilated buildings indicated the application of the model used in ASHRAE 55 as evaluation criteria for this research, determining the critical conditions and limits to thermal stress inside the apartments.

ASHRAE 55 standard proposed an adaptive model based on the research of [23] and a specific method for using it in naturally ventilated buildings situated in regions with average monthly temperatures between $10{ }^{\circ} \mathrm{C}$ and $33.5^{\circ} \mathrm{C}$. The method, which considers the absence of artificial air conditioning system and physical activity with low metabolic rates (between 1.0 met and 1.3 met), is applicable to environments in which the building occupant can control spatial options in order to adapt himself to the climatic variations (e.g. opening windows and changing clothes).

In sequence, an extensive analysis of the data on wind regime over the city of Fortaleza was perform to determine the main directions and initial velocity that should be adopted in computer simulations.

\subsection{Local wind patterns}

For a proper use of natural ventilation as a strategy for passive cooling of buildings, the frequency and intensity of the local wind should be consider, analyzing low wind speed periods. The existence of such periods, especially in warmer seasons and during daytime, prevents the adoption of this strategy [24]. 
However, the analysis and systematization of wind data period between 2002 and 2009 for the city of Fortaleza indicates a high potential for applying natural ventilation as a thermal comfort strategy due to its relatively constant frequency and intensity as shown by wind-rose plotted (figure 1) [20].

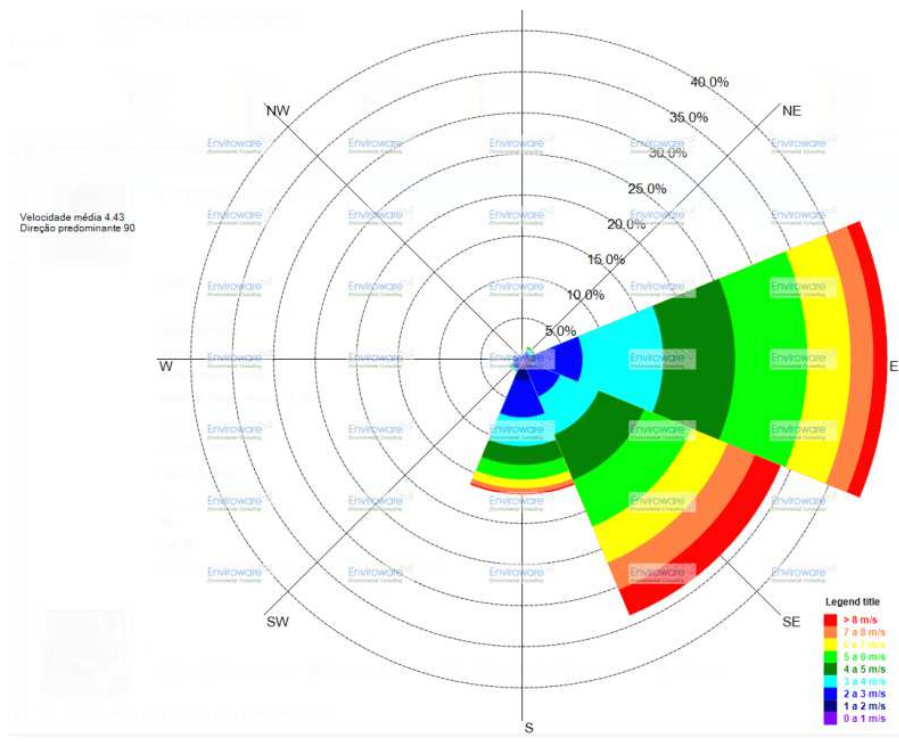

Figure 1. Wind-rose plotted for the city of Fortaleza after analyzing the period between 2002 and 2011.

In addition, higher air velocities are more frequent during the afternoon. During this period air temperature reaches higher values and, consequently, higher ventilation rates are more necessary to reach thermal comfort zone. However, analyzing this specific relation the results show that when air temperatures are higher, air velocity reach values up to $4 \mathrm{~m} / \mathrm{s}$, as shown by figure 2 [20].

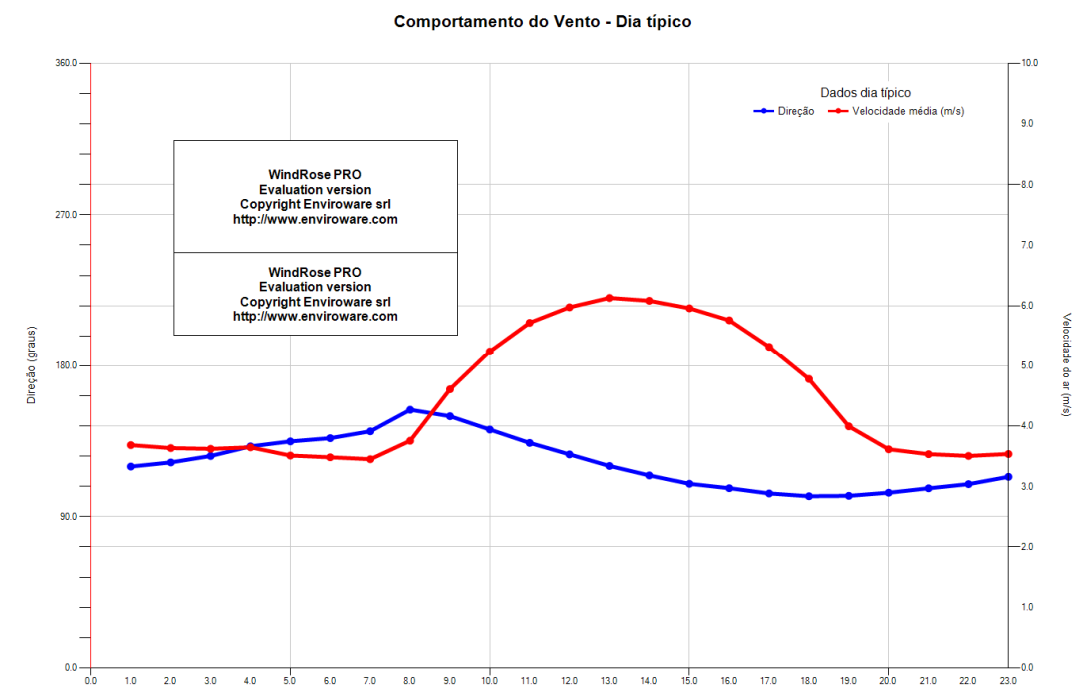

Figure 2. Typical wind day for the city of Fortaleza indicating the increasing in air speed as the temperatures rises and the little variation of the wind angles between 90 and 130 degrees. 
As indicated by the wind patterns characterization, only two predominant wind directions were determined: east and southeast directions. Therefore, a set of two different domains should be prepared in order to perform simulations of east wind $\left(90^{\circ}\right)$ with an initial velocity of $4,54 \mathrm{~m} / \mathrm{s}$, and simulate the southeast wind $\left(135^{\circ}\right)$ with $5,11 \mathrm{~m} / \mathrm{s}$ for initial speed (figure 3 ).

Domain's dimensions must be at least five times the height of the largest element simulated at the windward and its sides, six times from the ground to the top of it and fifteen times from the border of the elements simulated to the domain's end at the downwind area. The insertion of the model building with 24 floors $(72 \mathrm{~m})$ resulted in a rectangular domain with dimensions $1768 \mathrm{~m}$ x $1048 \mathrm{~m}$ x $432 \mathrm{~m}$ for both east and southeast models.

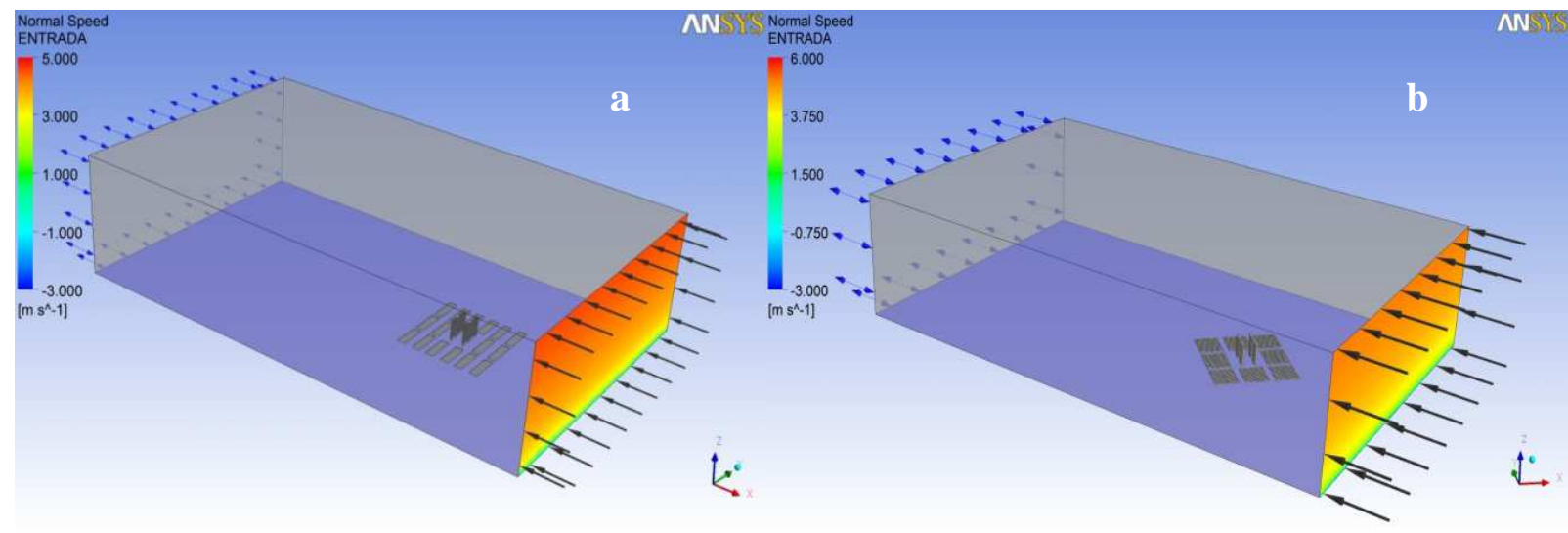

Figure 3. Both domains prepared to simulate east (a) and southeast (b) wind directions.

\subsection{Urban density scenarios}

Based upon the urban legislation for the city of Fortaleza, different urban density scenarios were modeled using a CAD tool. They express urban density as population to land area (inhabitants per hectare) and, at the present stage of this research, only represent low to medium densities, varying in a range from 80 to 640 people/hectare were modeled.

At the center of each scenario, four high-building models (72 $\mathrm{m}$ height) were arranged. Around this block, 8 blocks of $100 \mathrm{~m}$ x $100 \mathrm{~m}$ each were arranged. Each block was then divided into 20 lots of $50 \mathrm{~m}$ deep and 5 meters front that were occupied in accordance with actual urban legislation standards. The maximum occupancy rate was applied to model the buildings within these blocks in order to achieve the greatest construction potential allowed by urban legislation.

Modeling different scenarios in order to represent various urban density values also shows a wide range of possibilities regarding wind permeability. More compact and lower buildings contrast with higher forms with spaces between buildings. This analysis will evaluate some of the urban characteristics that affect natural ventilation potential inside dwellings.

In the simulations of each urban scenario only the east and southeast wind directions will be applied as initial and boundary conditions in the cfd tool. This choice is due to wind data analysis previously performed. 


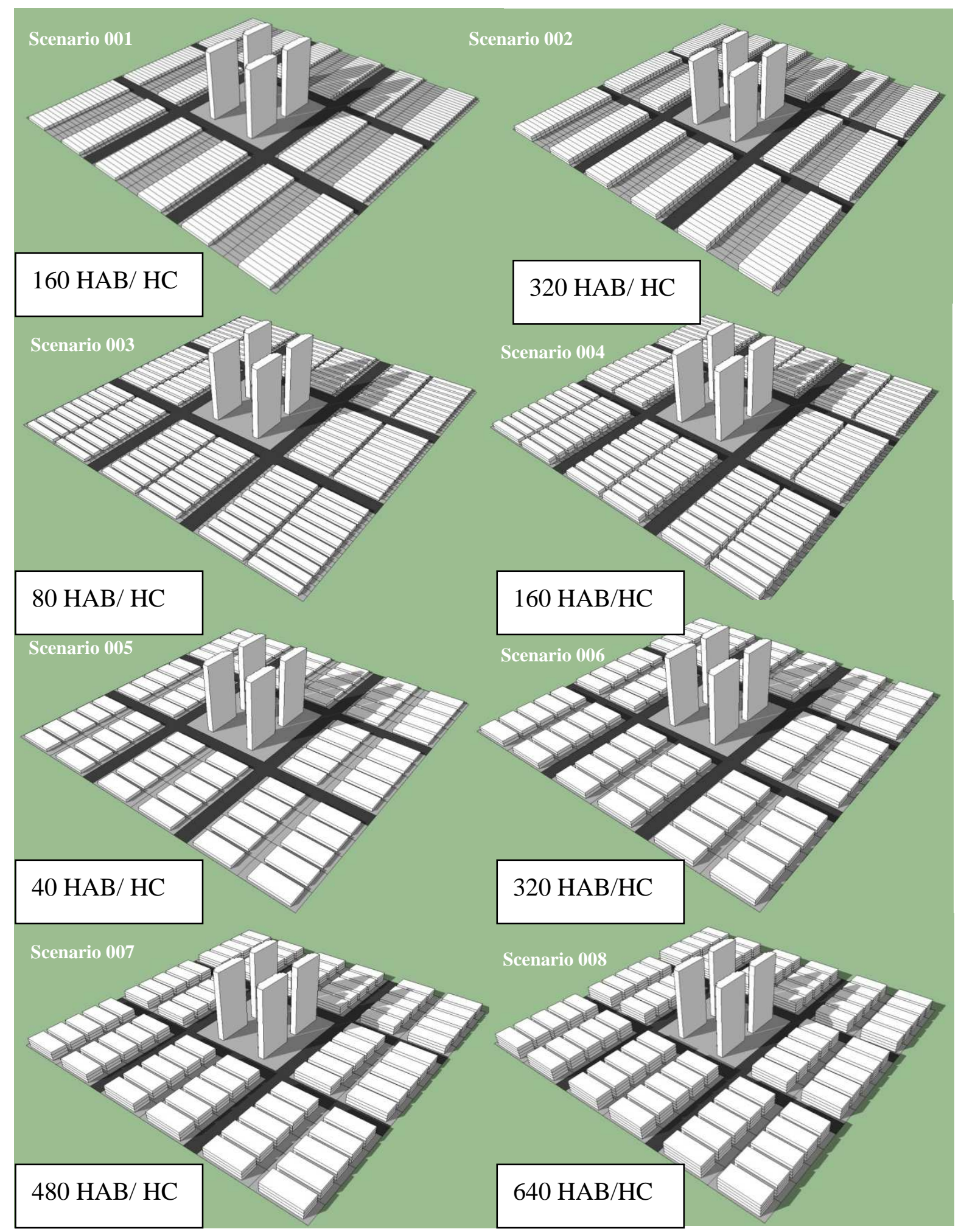

Figure 4. Eight different urban density scenarios simulated to calculate pressure coefficients on the model building's facades. 
However, due to computational capacity resources available, the study of natural ventilation patterns through openings will include windows only in previosly selected heights, simulating the airflow inside the apartment in the building's basis and in the higher floor of the model building in three rooms per floor, as shown by figure 5. Such simplification is necessary in order to generate appropriate mesh regarding to its quality and computational size. Therefore, the option for limiting the amount of openings to be analyzed in the airflow rate and pressure field according to each scenario created becomes crucial for simulation time and result's reliability.

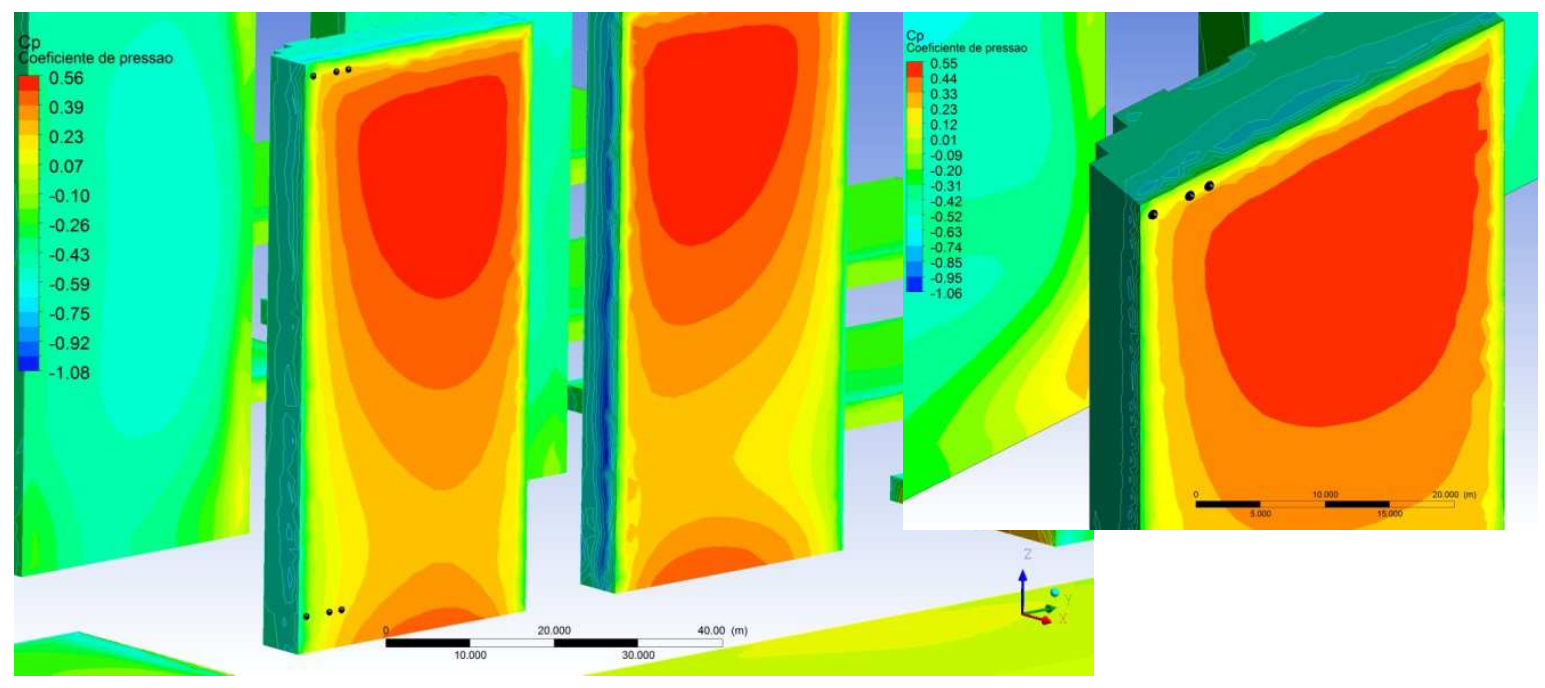

Figure 5. Six openings located at the basis and top of the model building's windward façade.

\subsection{The cfd tool used in the research}

For the study of natural ventilation in the urban environment and its effects on indoor air movement ANSYS-CFX software [25] will be used. There is a wide range of CFD applications available. However, the choice of using the ANSYS CFX is due to the software's license availability at the Laboratory of Environmental Comfort and Energy Efficiency (LABAUT). Also, the accumulated experience in using this application in previous researches also contributed to the choice of this particularly software.

The CFX is an example of cfd produced by the ANSYS Company that allows the simulation of any situation involving fluid mechanics in any scale and boundary conditions, as long as the computational capacity is provided.

The software consists of 4 modules. In the pre-processing level the geometry is prepared in CAD ambient by determining the area of the model to be adapted in ANSYS ICEM CFD for the development and parameterization of the mesh, defining the points where the equations should be calculated. For the model construction, the buildings are simplified, which reduces considerably the processing time and computational capacity for calculating the simulation. Then, the definition of the system simulation, equations to be calculated, the initial and boundary conditions and the turbulence model are adopted in CFX-Pre. 
The simulation is then calculated in the CFX-Solver and the results are viewed through three-dimensional images and graphics in CFX-Post, inserting points, lines and planes in various locations, allowing the visualization of the airflow in different parts of the model through velocity contours, vectors or streamlines.

For the study of natural ventilation patterns through openings the applied mesh in each scenario will include windows only in previosly selected heights, simulating the airflow inside the apartment in the building's basis, at its middle and on the top of the main building, as shown by figure 5. Such simplification is necessary due to the computational capacity availability, limitating the amount of openings to be analyzed in the airflow rate and pressure field according to each scenario created.

Some steps must be performed in order to make the simulations more efficient. Firstly, a few parametrical tests were accomplished to better describe and test different turbulence models provided by the simulation program applied in this research and then compare with others present in literature. Secondly, increasing parameters such as initial velocity input and surface roughness were evaluated in different simulations.

\subsection{Testing different turbulence models}

Turbulence is a highly complex physical phenomenon that significantly influences the behavior of fluids in flow [26].

CFD programs have several options for modeling the turbulence effect. However, they add little or no information about the advantages and disadvantages of each option available [15].

ANSYS CFX help guide has some information about available turbulence models. It explains that turbulence models with two equations are widely used due to its good relation between the computationL time and capacity and result's accuracy.

The $\mathrm{K}-\varepsilon$ model is a turbulence model in which two transport equations are calculated to determine the value of turbulent kinetic energy $(\mathrm{k})$ defined as the change of speed fluctuations and its dissipation rate $(\varepsilon)$. The standard model $\mathrm{K}-\varepsilon$ is quite common in researches related to fluid dynamics, despite advances in computing power and the increased use of other turbulence models, such as Large Eddy Simulation (LES). Also, the advantages of this model with emphasizes the relationship between result's quality and little processing capacity required $[15 ; 27]$.

RNG K - $\varepsilon$ model differs from the standard model once it considers the effects in small scales. Although the ANSYS CFX tutorial indicates that, commonly, this model shows a small improvement over the $\mathrm{K}-\varepsilon$ standard model, the RNG $\mathrm{K}-\varepsilon$ model had convergence problems, not reaching reliable results once it ended after 200 interactions (3 hours of computational processing) with residuals higher than $1 \times 10^{-4}$. Eddy Viscosity Transport Equation model reached the convergence criteria target (residuals less than $1 \times 10^{-4}$ ) after 89 interactions (1 hour and 9 minutes).

SSG Reynolds Stress model has six additional transport equations which are solved for each iteration. The terms present in the Reynolds stress equations are also more complex than 
in $\mathrm{K}-\varepsilon$ model. As a result of these factors, the convergence may be slower. Two attempts to simulate using this turbulence model returned an error after 143 interactions.

The shear-stress transport model was developed in order to effectively blend the robust and accurate formulation of the model $\mathrm{K}-\omega$ in the region close to the wall. The simulation using the Shear Stress Transport turbulence model reached the target criteria after 1,5 hour of calculations, surpassing 100 interactions and behaved quite balanced, performing quick calculations in comparison with other models.

Comparing the results in relation to processing time, the $K-\varepsilon$ standard model achieved better results and once little information is available about the eddy viscosity turbulence model, the $\mathrm{K}-\varepsilon$ standard model is applied to the simulations in this research. In addition, the use of more sophisticated models and whose quality is recognized in the literature as the "Detached eddy simulation" (DES) or "Large eddy simulation" (LES) is not yet a reality for the determination of pressure coefficient in everyday situations due to the high processing capabilities and storage required.

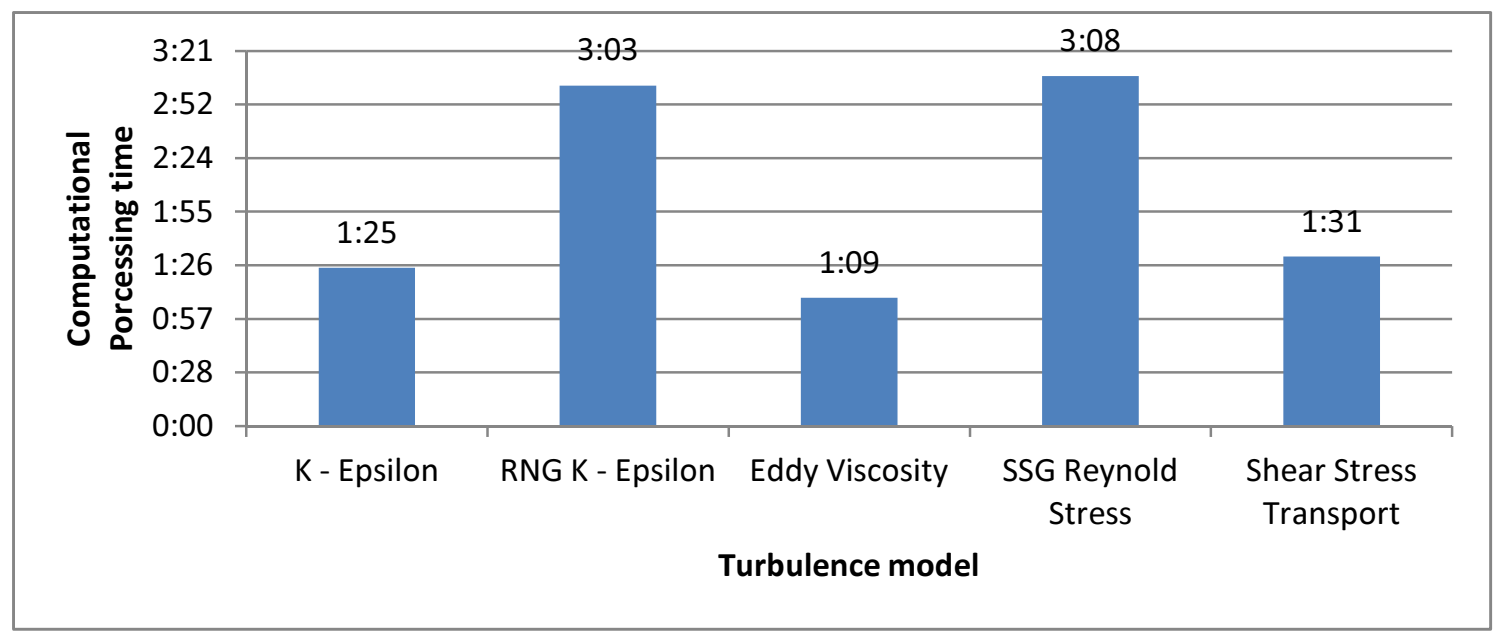

Figure 6. Processing time for each turbulence model tested.

\subsection{Varying initial conditions: velocity and roughness level}

A set of parametrical tests involving initial velocity and the roughness height were performed using scenario 001 in order to evaluate the influence of such parameters on pressure coefficient values over main building's façade.

Initially, four different roughness height values $(0.001 \mathrm{~m}, 0.01 \mathrm{~m}, 0.1 \mathrm{~m}$ and $0.3 \mathrm{~m})$ were defined using logarithmic profiles to test the influence of this parameter. As the initial air velocity was defined, simulations were performed in order to assess the impact of the floor roughness height over pressure coefficients for the scenario 001.

The pressure coefficients on the windward façade of the model building decreases as the roughness level applied to the model floor increases. One can observe through figure 7 that the area in which $\mathrm{Cp}$ reaches maximum values significantly decreases as the roughness 
level ranges from $0,001 \mathrm{~m}$ (figure 7a), a common value for off-sea wind or coastal areas, to $0,3 \mathrm{~m}$ (figure $7 \mathrm{~d}$ ), roughness height applied to areas with a few buildings or some trees.

In simulations which the lowest roughness value (0.001) was inputed, the red zone (Cp over 0.7 ) covers more than half of that building's façade. The size of this zone significantly decreases as the value of the roughness reaches values comparable to outskirts of towns and starts to encompass less than one third of the model building's windward façade area. Also, cp values close to building's basis suffer significant changes decreasing from 0.5 to 0.27 as the surface roughness reaches higher values. These data confirm the importance of the model's floor roughness level applied for simulations over pressure coefficient calculation.
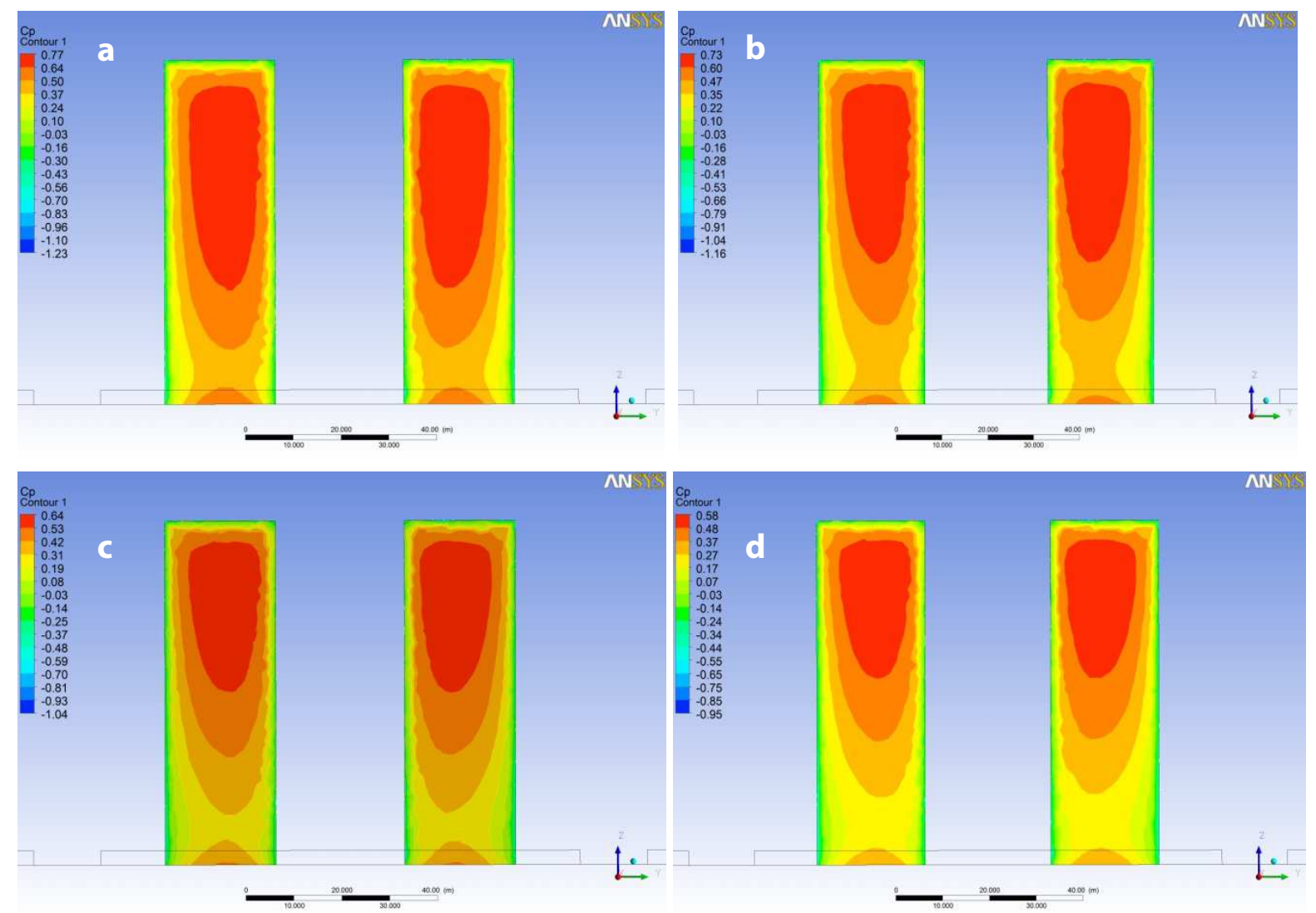

Figure 7. Results for pressure coefficients over the model building's façade after applying roughness levels of 0,001 (figure 7a); 0,01 (figure 7b); 0,1 (figure 7c); 0,3 (figure 7d).

More specifically, the reduction in minimal pressure coefficient values becomes quite evident as the floor roughness level inreases. In relation to the maximum values threre a reduction is also verified but it is less significant compared to the minimum values reached, as show by figure 7 . 


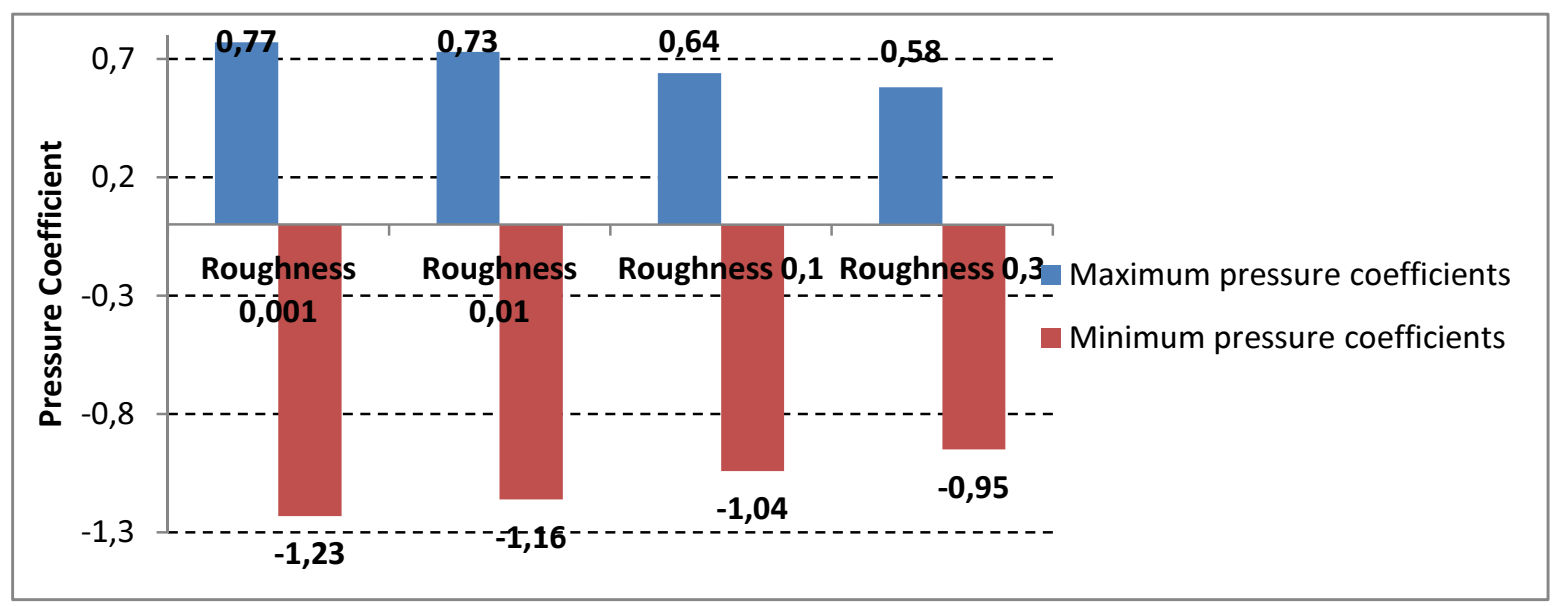

Figure 7. Results for pressure coefficients over the model building's façade after applying roughness levels of 0,001 (figure 7a); 0,01 (figure 7b); 0,1 (figure 7c); 0,3 (figure 7d).

Once $\mathrm{Cp}$ is influenced by the floor roughness, it was decided to analyze the effect of the initial velocity on pressure coefficients values over the model building's façade.

Thus, an initial speed of $4,54 \mathrm{~m} / \mathrm{s}$ was inputed for the first simulation. Then it was increased by $50 \%$, doubling and quadrupling it it for the other simulations. As one can observe in figure 8 , the red area maintains its dimensions, indicating little variation in as the initial speed increases from one test to another. Also the basis an areas of low pressure coefficients suffer little changes in values reached.

All simulations to evaluate the influence of initial velocity on the pressure coefficients were similar, reaching residuals target after 95 interactions (less than one hour of calculations).

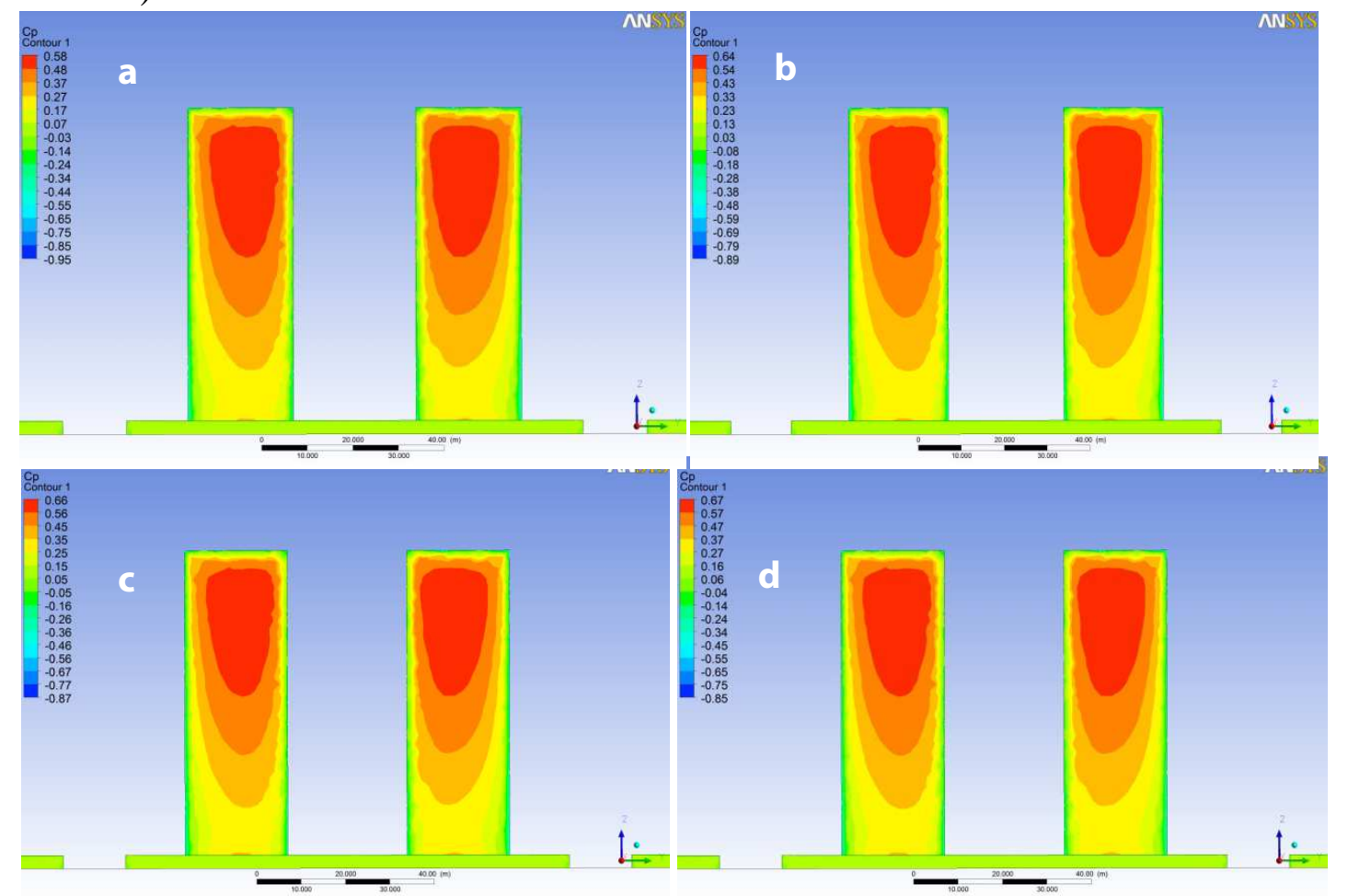

Figure 8. Results for pressure coefficients over the windward façade varying the initial velocity input from $4.54 \mathrm{~m} / \mathrm{s}$ (a) $6.81 \mathrm{~m} / \mathrm{s}$ (b) $9.08 \mathrm{~m} / \mathrm{s} \mathrm{(c)} \mathrm{and} 13.62 \mathrm{~m} / \mathrm{s} \mathrm{(d).}$ 
Unlike the effect of different roughness floor levels, the results for different initial velocity inputs indicate discrete changes even with an increase of $200 \%$ on the initial velocity input.

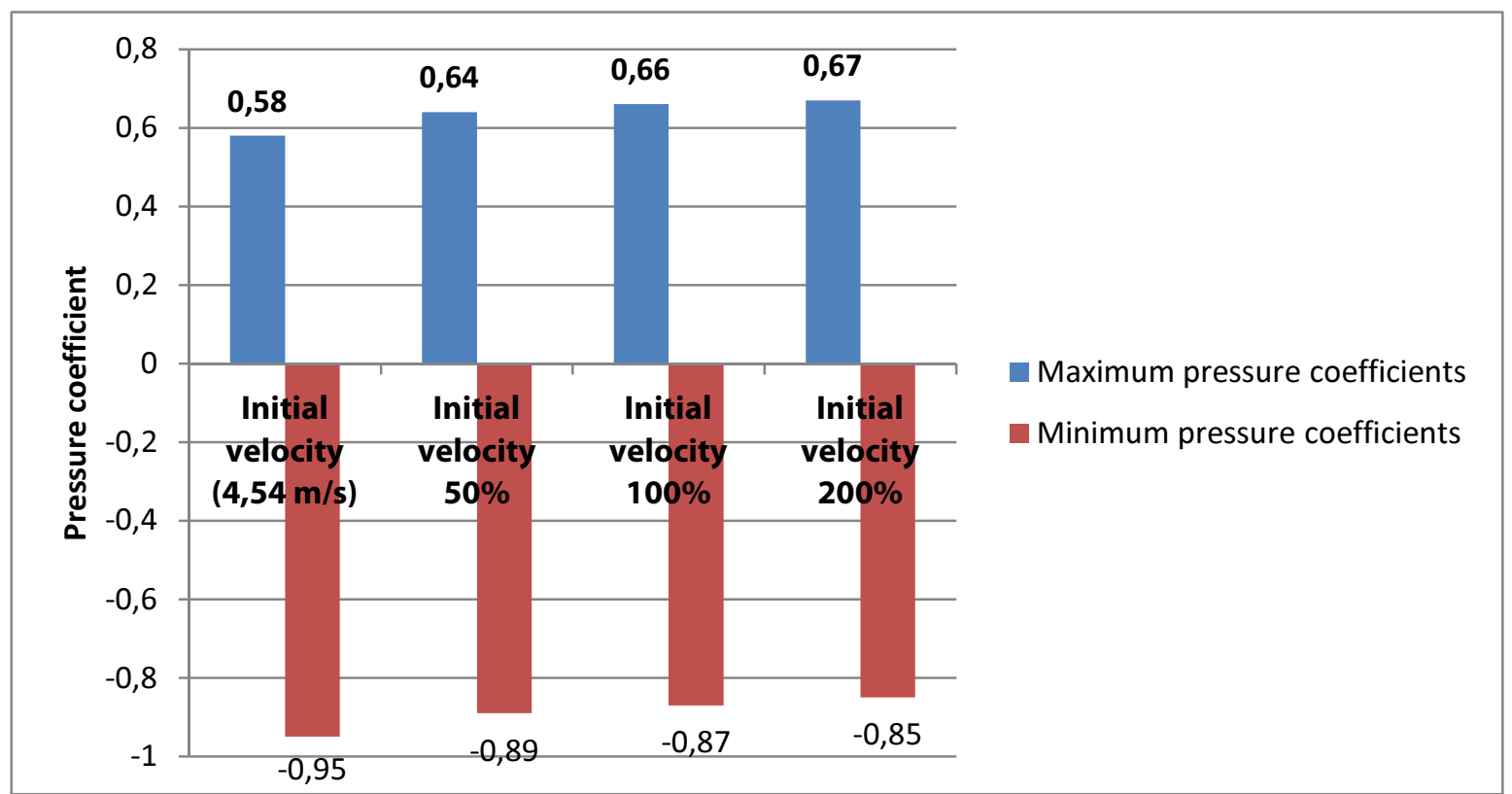

Figure 9. Results for pressure coefficients over the windward façade varying the initial velocity input from $4.54 \mathrm{~m} / \mathrm{s}$ (a) $6.81 \mathrm{~m} / \mathrm{s}$ (b) $9.08 \mathrm{~m} / \mathrm{s}$ (c) and $13.62 \mathrm{~m} / \mathrm{s}$ (d).

\section{PRELIMINARY PRESSURE COEFFICIENTS RESULTS}

In this section, preliminary results for pressure coefficient over the model building's façade are presented.

For east wind $\left(90^{\circ}\right)$, increasing the space between buildings in scenarios 003 to 008 raised pressure coefficients at the bottom and at the top of the building in almost every scenario. On the other hand, pressure coefficient for building basis at rooms 1 and 2 is higher. This is due to elevation of the wind gradient as the result of lower buildings $(3 \mathrm{~m}$ and $6 \mathrm{~m}$ height) close to the windward façade of the model building. Usually, pressure coefficient values calculate for rooms in floor 24 are higher, onde wind pressure and speed increase with height, these points higher values are in accordance to the wind gradient characteristics.

Room 3 window is positioned close to the model building's corner. This specific position profoundly change pressure coefficients values. As one can observe, even though this window is positioned on the windward façade the calculated values indicate them as negative, such characteristic is common to pressure coefficients over leeward façades. Therefore, a review is necessary in order to present reliable values for this specific position.

Higher $\mathrm{Cp}$ values were registered for southeast simulations. The model building position in relation to the wind direction (a 45 degrees angle) determined a higher pressure field in the corner region of the model building. However, in other areas $\mathrm{Cp}$ values were lower in comparision to the east wind direction simulations. Most of all, the inclined position of buildings is responsible for increasing the pressure field values in the corner of the building. However, the flow separation due to the corners decreases the $\mathrm{Cp}$ values in other 
areas as regions of the model.

Elavating building's height generated higher $\mathrm{Cp}$ values specially in rooms 1 and 3 in the southeast simulations, attesting that the increasing in the layer close to other building's tops resulted in better ventilation conditions. But further investigations should be performed.

Some aspects such as the space between buildings and the increasing in urban density are not quite evaluated and still need further investigations and simulations. Also, scenarios 007 and scenario 008 didn't reach the residuals target even after 200 interations for simulations with southeast wind direction. These scenarios should be simulated again changing mesh characteristics in order to achieve reliable results in convergence criteria.

Table 1. Pressure coefficient preliminary results for rooms 1,2 and 3 at the building's basis and higher floor.

\begin{tabular}{|c|c|c|c|c|c|c|c|}
\hline \multirow{3}{*}{ Scenario } & \multirow{3}{*}{ Floor } & \multicolumn{6}{|c|}{ Pressure Coefficients (Cp) (dimensionless) } \\
\hline & & \multicolumn{3}{|c|}{ East Wind $\left(90^{\circ}\right)$} & \multicolumn{3}{|c|}{ Southeast Wind $\left(135^{\circ}\right)$} \\
\hline & & $\begin{array}{c}\text { Room } 1 \\
\text { (P1) }\end{array}$ & $\begin{array}{c}\text { Room } 2 \\
\text { (P2) }\end{array}$ & $\begin{array}{c}\text { Room } 3 \\
\text { (P3) }\end{array}$ & $\begin{array}{c}\text { Room } 1 \\
\text { (P1) }\end{array}$ & $\begin{array}{c}\text { Room } 2 \\
\text { (P2) }\end{array}$ & $\begin{array}{c}\text { Room } 3 \\
\text { (P3) }\end{array}$ \\
\hline \multirow[t]{2}{*}{001} & Floor 1 & 0,18 & 0,12 & $-0,16$ & 0,26 & 0,23 & 0,08 \\
\hline & Floor 24 & 0,13 & 0,20 & $-0,11$ & 0,18 & 0,23 & 0,40 \\
\hline \multirow[t]{2}{*}{002} & Floor 1 & 0,22 & 0,16 & $-0,10$ & 0,27 & 0,25 & 0,11 \\
\hline & Floor 24 & 0,12 & 0,14 & 0,16 & 0,21 & 0,21 & 0,41 \\
\hline \multirow[t]{2}{*}{003} & Floor 1 & 0,21 & 0,14 & $-0,15$ & 0,28 & 0,25 & 0,04 \\
\hline & Floor 24 & 0,25 & 0,25 & 0,02 & 0,22 & 0,19 & 0,38 \\
\hline \multirow[t]{2}{*}{004} & Floor 1 & 0,18 & 0,11 & $-0,13$ & 0,26 & 0,22 & 0,09 \\
\hline & Floor 24 & 0,22 & 0,22 & $-0,05$ & 0,25 & 0,26 & 0,33 \\
\hline \multirow[t]{2}{*}{005} & Floor 1 & 0,19 & 0,12 & $-0,11$ & 0,26 & 0,24 & 0,15 \\
\hline & Floor 24 & 0,18 & 0,18 & 0,10 & 0,26 & 0,24 & 0,54 \\
\hline \multirow[t]{2}{*}{006} & Floor 1 & 0,19 & 0,14 & $-0,14$ & 0,26 & 0,23 & 0,01 \\
\hline & Floor 24 & 0,21 & 0,17 & 0,23 & 0,30 & 0,32 & 0,50 \\
\hline \multirow[t]{2}{*}{007} & Floor 1 & 0,18 & 0,13 & $-0,11$ & - & - & - \\
\hline & Floor 24 & 0,21 & 0,17 & 0,01 & - & - & - \\
\hline \multirow[t]{2}{*}{008} & Floor 1 & 0,20 & 0,15 & $-0,19$ & - & - & - \\
\hline & Floor 24 & 0,23 & 0,23 & $-0,06$ & - & - & - \\
\hline
\end{tabular}

\section{NEXT STEPS: CALCULATING AIRFLOW RATES FOR EACH SCENARIO}

Airflow rates inside the apartments will be calculated using pressure coefficients (Cps) over the model building's facades as a result of the wind simulations for each urban density scenario designed.

Airflow rates inside the main building will be calculated using equation 1, which takes 
the size and discharge characteristics of each of the openings involved in the simulation.

$$
Q=\left[\frac{\left(C p_{1}-C p_{n+1}\right)}{\frac{1}{C d_{1}^{2} A_{1}^{2}}+\frac{1}{C d_{2}^{2} A_{2}^{2}}+\ldots+\frac{1}{C d_{n}^{2} A_{n}^{2}}}\right]^{0,5}
$$

Where: $Q=$ airflow rate

$\mathrm{Cp}_{1}=$ Pressure coefficient on inlet opening

$\mathrm{Cp} \mathrm{p}_{\mathrm{n}+1}=$ Pressure coefficient on outlet opening

$\mathrm{V}_{\mathrm{z}}=$ air speed on the opening height $(\mathrm{m} / \mathrm{s})$

$\mathrm{Cd}_{1}=$ Discharge coefficient of the opening

$\mathrm{A}_{1}=$ Inlet opening aera $\left(\mathrm{m}^{2}\right) \times$ cosine the wind incidence angle

$\mathrm{Cd}_{2}=$ Discharge coefficient for internal openings

$\mathrm{A}_{2}=$ Internal opening area $\left(\mathrm{m}^{2}\right)$

$\mathrm{Cd}_{\mathrm{n}}=$ Discharge coefficient for outlet

$A_{n}=$ Outlet opening area $\left(\mathrm{m}^{2}\right)$

Based on simulation results and airflow rates inside the model building, an electronic matrix will be elaborated in order to relate the numerical field of pressure coefficients on the model building's façade in each scenario and its effects on indoor airflow. Changes in air speed and the necessary flow to maintain acceptable operating temperature values are determined by the adaptive temperature chart, as shown by figure 10 [23]. The mean radiant temperature (TRM) should be calculated for the hypothetical flat inside the main building in the simulations. The dry bulb temperature (TS) is taken from the weather data for Fortaleza and the radiant thermal exchange coefficient is considered as a fixed value for indoor simulations.

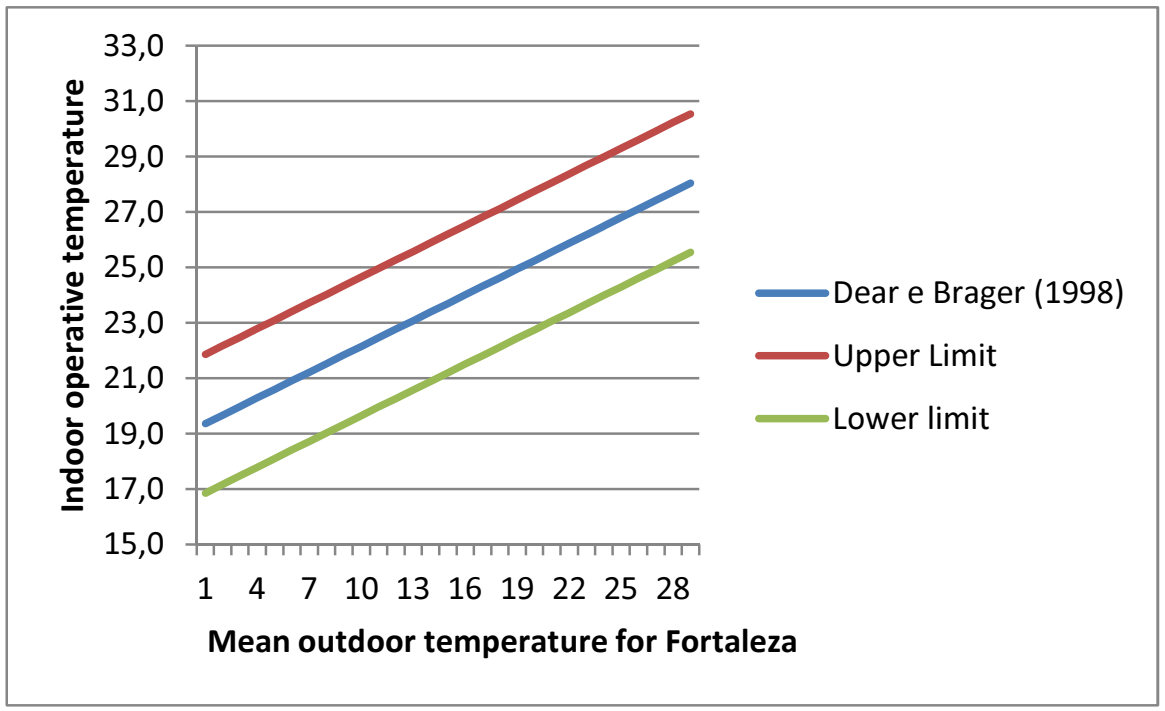

Figure 10. Acceptable temperature ranges in naturally ventilated buildings according to average mean monthly temperature for Fortaleza 


\section{Acknowledgements}

This research is financially supported by State of São Paulo’s Foundation for Research Support (FAPESP).

\section{REFERENCES}

[1] Chandler, T. J. "Urban Climatology and its Relevance to Urban Design". Geneva, WMO. Technical Note 149, 1976.

[2] Oke, T. R. "Boundary Layer Climates". 2 ed. London: Methuen, 1987.

[3] Oke, T. R. The urban energy balance. Progress in Physical Geography. 12, 1988.

[4] Bitan, A. The high climatic quality city of the future. Atmospheric Environment. 26B, 1992.

[5] Katzschner, L. Urban climate studies as tools for urban planning and architecture. In: IV Encontro Nacional de Conforto no Ambiente Construído. Salvador, 1997.

[6] Assis, E. S. Impactos da forma Urbana na Mudança Climática: Método para a previsão do Comportamento Térmico e melhoria de Desempenho no Ambiente Urbano. PhD thesis. Doutorado em Estruturas Ambientais Urbanas. Faculdade de Arquitetura e Urbanismo, Universidade de São Paulo, São Paulo, 2000.

[7] Duarte, D. H. S. Padrões de ocupação do solo e microclimas urbanos na região de clima tropical continental. PhD thesis. Faculdade de Arquitetura e Urbanismo da Universidade de São Paulo, São Paulo, 2000.

[8] International Energy Agency (IEA). World Energy Outlook 2008, Paris, France. Available from: http://www.worldenergyoutlook.org/docs/weo2008/WEO 2008_es_english.pdf [accessed 4/21/2009].

[9] International Energy Agency (IEA). Key World Energy Statistics, 2006.

[10] Pérez-lombard, L.; Ortiz, J.; Pout, C. A review on buildings energy consumption information. Energy and Buildings. 40, 394 - 398, 2008.

[11] Frota, A. B.; Schiffer, S. R. Manual de conforto térmico. Editora Nobel, 4 ed., São Paulo, 2000.

[12] Yarke, E. Ventilación natural de edificios. Nobuko: Buenos Aires, 2005.

[13] Liddament, M. W. (Ed). Air infiltration calculation techniques - an applications guide. AIVC: Great Britain, 1986.

[14] Allard, F. (Ed.). Natural ventilation in buildings: a design handbook. James \& James: London: 1998.

[15] Cóstola, D., Alucci, M. P. Aplicação de CFD para o cálculo de coeficientes de pressão externos nas aberturas de um edifício. Ambiente Construído. 11, n. 1, p. 145-158, Porto Alegre, 2011.

[16] Costola, D., Blocken, B., Hensen, J. Overview of pressure coefficient data in building energy simulation and airflow network programs. Building and Environment. 44, 20272036, 2009.

[17] Carrilho da Graça, G.; Chen, Q.; Glicksman, L. R.; Norford, L. K. Simulation of winddriven ventilative cooling systems for an apartment building in Beijing and Shanghai. Energy and Buildings. 34, $1-11,2002$.

[18] Prata, A. R. Impacto da altura de edifícios nas condições de ventilação natural do meio 
urbano. 2005. PhD Thesis. Faculdade de Arquitetura e Urbanismo, Universidade de São Paulo. São Paulo, 2005.

[19] Wang, L.; Wong, N. H. Coupled simulations for naturally ventilated rooms between building simulation (BS) and computational fluid dynamics (CFD) for better prediction of indoor thermal environment. Building and Environment. 44, 95 - 112, 2009.

[20] Leite, R. C. V. Fortaleza: terra do vento a influência da mudança nos padrões de ocupação do solo sobre a ventilação natural em cidade de clima tropical úmido. Master dissertation. Faculdade de Arquitetura e Urbanismo, Universidade de São Paulo. São Paulo, 2010.

[21] Asfour, O. S. Prediction of wind environment in different grouping patterns of housing blocks. Energy and Buildings. 42, 2061 - 2069, 2010.

[22] Cheung, J. O. P.; Liu, C. CFD simulations of natural ventilation behaviour in high-rise buildings in regular and staggered arrangements at various spacings. Energy and Buildings. 43, 1149 - 1158, 2011.

[23] Brager, G. S.; Dear, R. J. Thermal adaptation in the built environment: a literature review. Energy and Buildings. 27, 1998.

[24] Bittencourt, L.; Cândido, C. Introdução à ventilação natural. EDUFAL: Maceió, 2005.

[25] ANSYS. Computational fluid dynamic solutions. Canonsburg: ANSYS, 2005. Disponível em http://www.ansys.com/assets/brochures/cfd-solution-10.pdf acessed in 10/06/2011.

[26] Davidson, P. A. Turbulence: an introduction for scientists and engineers. Oxford University Press: Oxford, 2004. 